\title{
KOMPETENSI PEDAGOGIK YESUS BERDASARKAN MATIUS 5-7 DAN IMPLEMENTASINYA DALAM PELAYANAN SEKOLAH MINGGU
}

\section{Simon Runtung, Rini Bunga}

Sekolah Tinggi Teologi Kibaid Makale

\begin{abstract}
Jesus Christ is the Great teacher of great influence. Every teacher who wants to be successful must learn from Jesus who has pedagogical competence based on Matthew 5-7. The purpose of this study was to find the reasons why Jesus 'pedagogical competence based on Matthew 5-7 had not had a maximum impact and to find the implementation of Jesus' pedagogical competence in Sunday school teaching at the KIBAID Church in Tombang Congregation. The research method used is qualitative with data collection techniques through observation and interviews. The informants involved were pastors, elders, Sunday school teachers, and parents. The results showed that the cause of Jesus' pedagogical competence based on Matthew 5-7 had not had a maximum impact on Sunday School teaching in the KIBAID Church of the Tombang Congregation due to lack of lesson planning preparation, lack of skill in choosing and using appropriate teaching strategies, lack of creativity in developing teaching methods. Therefore, it is necessary that Jesus' pedagogical competence based on Matthew 5-7 needs to be implemented with full love and attention to students, able to direct students, base teaching with prayer, and guide students to practice the truth.
\end{abstract}

\begin{abstract}
Abstrak. Yesus Kristus adalah guru Agung yang sangat berpengaruh. Setiap guru yang ingin berhasil, harus belajar kepada Yesus yang memiliki kompetensi pedagogik berdasarkan Matius 5-7. Tujuan penulisan adalah untuk menemukan alasan kompetensi pedagogik Yesus berdasarkan Matius 5-7 belum berdampak secara maksimal dan menemukan implementasi kompetensi pedagogik Yesus dalam pengajaran Sekolah Minggu di Gereja KIBAID Jemaat Tombang. Metode penelitian yang digunakan ialah kualitatif dengan tehnik pengumpulan data melalui observasi dan wawancara di Gereja KIBAID Jemaat Tombang. Informan yang dilibatkan ialah pendeta, penatua, guru Sekolah Minggu, dan orang tua anak Sekolah Minggu. Hasil penelitian menunjukkan penyebab kompetensi pedagogik Yesus berdasarkan Matius 5-7 belum berdampak secara maksimal dalam pengajaran Sekolah Minggu di Gereja KIBAID Jemaat Tombang karena kurangnya persiapan perencanaan pembelajaran, belum terampil dalam memilih dan menggunakan strategi mengajar yang tepat, kurangnya kreatifitas mengembangkan metode mengajar. Sebab itu perlu kompetensi pedagogik Yesus berdasarkan Matius 5-7 perlu diimplementasikan dengan enuh kasih dan
\end{abstract}


perhatian terhadap peserta didik, mampu mengarahkan peserta didik, melandasi pengajaran dengan doa, dan menuntun peserta didik melakukan kebenaran.

\section{PENDAHULUAN}

Kompetensi pedagogik adalah kemampuan mendidik yang berkaitan dengan perancangan dan pelaksanaan pembelajaran, evaluasi hasil belajar, serta pengembangan peserta didik (Muliayan 2010). Kompetensi ini sangat penting dalam peningkatan kualitas pembelajaran. Guru yang memiliki kompetensi pedagogik mampu menuntun peserta didik mencapai prestasi yang maksimal (Rosyada 2017).

Yesus dikenal sebagai Guru Agung yang sangat berpengaruh. Nainggolan mengatakan bahwa setiap pendidik yang ingin berhasil dalam mengajarkan kebenaran Firman Allah haruslah belajar kepada Yesus (Nainggolan 2007). Ento juga mengatakan bahwa guru Kristiani yang profesional harus meneladani Yesus (Ento 2019).

Teladan kompetensi pedagogik Yesus sangat menojol dalam Matius 57. Pengajaran Yesus di Bukit membuat pendengarnya menjadi takjub (Mat. 7:28-29). Awal pasal 5 Yesus memulai pengajaran yang menarik dan akhir pasal 7 para pendengar menjadi takjub pada pengajaran-Nya.

Tugas mengajar Yesus nyata dalam kehidupan dan pelayanan-Nya. Sidjabat mengatakan bahwa la memperkenalkan Allah melalui kegiatan mengajar, berkhotbah, mengadakan mujizat dan mendemonstrasikan teladan 
hidup yang unik. Dalam Injil Matius Yesus mengajar berdasarkan otoritas, wibawa dan kuasa sehingga orang yang mendengar menjadi takjub, terpukau dan memberi respon positif (Sidjabat 2009).

Tuhan Yesus telah memberi amanat agung dalam Matius 28:19-20 untuk menjadikan semua bangsa murid Kristus dan mengajarkan segala sesuatu yang sesuai dengan perintah-Nya. Tentu saja untuk mengajarkan amanat tersebut membutuhkan kompetensi pedagogik.

Berdasarkan survei kepada enam Guru Sekolah Minggu (GSM), di Gereja KIBAID Jemaat Tombang, ternyata mereka belum maksimal memahami dan menerapkan tentang kompetensi pedagogik Yesus. Oleh karena itu belum berdampak secara maksimal pula kepada anak Sekolah Minggu di gereja tersebut.

Tujuan penelitian ini adalah untuk menemukan penyebab kompetensi pedagogik Yesus berdasarkan Matius 5-7 belum diterapkan secara maksimal oleh GSM dan untuk menemukan implementasi kompetensi pedagogik Yesus berdasarkan Matius 5-7 dalam pengajaran sekolah Minggu di Gereja KIBAID Jemaat Tombang.

\section{METODE PENELITIAN}

Jenis penelitian yang digunakan ialah penelitian kualitatif dengan metode deskriptif yaitu memaparkan hasil penelitian dengan kata-kata yang jelas dan terinci berdasarkan data kualitatif. Tehnik pengumpulan data 
melalui observasi dan wawancara. Untuk memperoleh data tentang objek, peneliti mengadakan observasi secara langsung di Gereja KIBAID Jemaat Tombang. Sumber data wawancara ialah pendeta, penatua, GSM, dan orang tua anak Sekolah Minggu di Gereja KIBAID Jemaat Tombang.

\section{HASIL PENELITIAN}

Hasil penelitian tentang alasan kompetensi pedagogik Yesus berdasarkan Matius 5-7, belum berdampak secara maksimal di di Sekolah Minggu Gereja KIBAID Jemaat Tombang-Sangalla' yaitu: kurangnya persiapan GSM dalam merencanakan pembelajaran. GSM belum terampil memilih dan menggunakan strategi mengajar. Mereka kurang kreatif dalam menggunakan dan mengembangkan metode mengajar, juga belum trampil menyusun isi pembelajaran dan belum trampil menutup pelajaran.

Cara mengimplementasikan kompetensi pedagogik Yesus di kalangan GSM gereja KIBAID Jemaat Tombang Sangalla' berdasarkan pengajaran Yesus pada Matius 5-7 yaitu: penuh perhatian dan kasih terhadap peserta didik, mampu mengarahkan peserta didik, melandasi pengajaran dengan doa dan menuntun peserta didik melakukan kebenaran.

\section{PEMBAHASAN}

Subyek penelitian ini adalah GSM di Gereja KIBAID Jemaat Tombang seperti pada tabel 1. 
Jurnal Misioner

p-ISSN: 2776-494X ; e-ISSN: 2776-4958

www.jurnal.sttkibaid.ac.id//Vol. 1 No. 1 (2021), hal. 99-120

Tabel 1. Data GSM Gereja KIBAID Jemaat Tombang

\begin{tabular}{|c|l|l|c|c|}
\hline No & \multicolumn{1}{|c|}{ Nama Guru } & \multicolumn{1}{|c|}{ Tempat Tanggal Lahir } & Pend.Terakhir & Pekerjaan \\
\hline 1. & $\begin{array}{l}\text { Syani B. Rante } \\
\text { Salu }\end{array}$ & Tana Toraja, 28 Agts 1989 & S2 PAK & PNS (Dosen) \\
\hline 2. & Risa Kulla' Padang & Tana Toraja, 11 Nop. 1974 & SMA & $\begin{array}{c}\text { Ibu rumah } \\
\text { tangga }\end{array}$ \\
\hline 3. & Akhim Mentang & Sangalla', 26 Maret 1982 & D3 Teologi & Staff PPA \\
\hline 4. & Jensi Pero & Kote', 28 Oktober 1999 & SMA & Mahasiswi \\
\hline 5. & Tiara Tandi Sakka' & Tondok Iring, 25 Juni 2000 & SMA & Mahasiswi \\
\hline 6. & Libertus Bulean & Tana Toraja,03 Juli 2000 & SMA & Mahasiswa \\
\hline
\end{tabular}

Dari tabel di atas menunjukkan bahwa GSM memenuhi standar mengajar.

Adapun kegiatan Sekolah Minggu yakni ibadah rutin setiap hari Minggu yang dimulai pada pukul 07.30-08.30 WITA, ibadah kebaktian doa setiap hari Jumat dimulai pada pukul 15.00-16.00 WITA, kegiatan SPS dilaksanakan setiap hari Jumat dan Sabtu, di mana dalam kegiatan ini anak Sekolah Minggu diberi pengajaran juga mereka membuat suatu kreasi atau kerajinan, dan juga ibadah pertemuan bulanan yang dilaksanakan oleh Klasis Sangalla' 1 kali dalam 2 bulan di minggu terkahir.

Tabel 2. Klasifikasi Berdasarkan Kelas yang Diajar

\begin{tabular}{|c|l|c|c|}
\hline No & \multicolumn{1}{|c|}{ Nama } & Kelas & Umur Anak \\
\hline 1 & Syani Bombongan Rante Salu & Remaja & $13-16$ tahun \\
\hline 2 & Akhim Mentang & Kelas Besar & $10-12$ tahun \\
\hline 3 & Risa Kulla Padang & Kelas Batita/Balita & $1-5$ tahun \\
\hline 4 & Jensi Pero & Kelas Batita/Balita & $1-5$ tahun \\
\hline 5 & Tiara Tandi Sakka' & Kelas Tengah & $6-9$ tahun \\
\hline 6 & Libertus Bulean & Kelas Tengah & $6-9$ tahun \\
\hline
\end{tabular}

Berdasarkan hasil observasi dan wawancara, maka diinterpretasikan tentang alasan kompetensi pedagogik guru Sekolah Minggu di Gereja 
KIBAID Jemaat Tombang berdasarkan Matius 5-7 belum berdampak secara maksimal kepada anak Sekolah Minggu karena kurangnya persiapan dalam merencanakan pembelajaran.

\section{Ketrampilan Yesus Dalam Merencanakan Pembelajaran}

Ketrampilan Yesus merencanakan pembelajaran nampak dalam hal memperhatikan kebutuhan orang yang diajar (Matius 5:3-12) dan menguasai tujuan pengajaran-Nya (Matius 7:21-23).

\section{Memperhatikan Kebutuhan}

Khotbah Yesus di bukit (5:3-12), Yesus memulai pengajaran-Nya dengan ucapan berbahagia. Kata dasar berbahagia yaitu 'bahagia' dalam bahasa Yunaninya makarios yang artinya sukacita yang tidak terganggu oleh perubahan situasi hidup. Sukacita tersebut tidak seorangpun dapat mengambilnya (Yoh.16:22). Inilah kebutuhan manusia sepanjang jaman. Menurut Talan, dalam khotbah-Nya di bagian pertama Yesus menekankan prinsip berbahagia dan kebenaran mutlak dalam Yesus (Talan 2020). Para pengikut-Nya sedang mengalami kesengsaraan, penderitaan, ketakutan yang menyiksa pada waktu itu. Hal ini sejalan dengan pendapat Verkuyl bahwa bahwa Yesus datang ke dunia untuk menyelamatkan manusia yang sengsara, supaya manusia sungguh-sungguh berbahagia selama-lamanya (Verkuyl 2002). 
Darmawan mengatakan bahwa Yesus memulai pengajaran-Nya dengan memperhatikan kebutuhan pendengar-Nya (Darmawan 2014). Kebutuhan pendengar pada saat itu adalah keselamatan dan cara hidup di hadapan Allah. Mereka perlu dituntun untuk memahami kerajaan sorga, sebab seperti dikatakan Brake, tujuan Yesus datang ke dunia bukan memisahkan orang benar dan orang berdosa, tetapi membuat orang berdosa menjadi benar (Brake 2019).

\section{Menguasai Tujuan}

Hamalik mengatakan kegiatan pengajaran adalah proses mencapai tujuan pendidikan (Hamalik 2009). Dalam dunia pendidikan sebelum guru melaksanakan pembelajaran harus menyusun tujuan yang hendak dicapai. Matius 7:21-23, ada tujuan pengajaran Yesus kepada murid-murid-Nya dan semua yang mendengar-Nya agar melakukan kehendak Bapa dan masuk ke dalam kerajaan sorga.

Persiapan yang saksama dilakukan agar tujuan pembalajaran dapat tercapai. Homrighausen dan Enklaar mengatakan bahwa setiap pekerjaan jangka panjang dan bersifat menentukan, seperti pendidikan memerlukan perencanaan yang teliti (Homrighausen dan Enklaar 2013). Sama halnya dengan Yesus, dalam melakukan pengajaran membuat perencanaan yang matang dengan menyusun tujuan hendak dicapai. Sumiyatiningsih mengatakan bahwa Tuhan Yesus tahu betul cara merancang pengajaran dan 
menyampaikannya dengan baik kepada pendengar-Nya sehingga para pendengar tahu arah, maksud, dan tujuan Yesus (Sumiyatiningsih 2006).

Yesus mempunyai tujuan dari pengajaran-Nya serta berusaha mencapai tujuan itu. Prince memaparkan tujuan konkrit Yesus secara khusus, yakni membentuk cita-cita luhur, menanamkan keyakinan yang teguh, memulihkan hubungan dengan Allah, memperbaiki hubungan dengan orang lain, menghadapi masalah hidup, membina watak yang kuat serta melatih untuk pelayanan (Prince 1975). Tuhan Yesus menguasai tujuan pengajaran yang disampaikan dan memiliki kompetensi mengajar dengan bagus. Hidup-Nya sesuai dengan ajaran-Nya sehingga Nikodemus mengatakan bahwa Yesus memang diutus oleh Allah (Sumiyatiningsih 2006).

Penelitian terhadap 6 guru Sekolah Minggu ditemukan bahwa guru Sekolah Minggu di Gereja KIBAID Jemaat Tombang kurang persiapan dalam merencanakan pembelajaran, baik persiapan pribadi, persiapan materi, maupun persiapan secara bersama-sama. Mereka belum memikirkan tentang kebutuhan dan tujuan secara matang sebelum mengajar. Akibatnya guru tidak dapat mengajar dengan efektif dan tidak berhasil maksimal.

\section{Terampil Memilih dan Menggunakan Strategi}

Menurut Edison strategi adalah rencana yang cerdas, cermat, dan teliti dengan mempertimbangkan berbagai aspek (positif-negatif, untung-rugi, bahaya-keuntungan dan lain-lain) untuk mencapai tujuan yang ditetapkan 
secara spesifik. Kata strategi sebenarnya merupakan istilah dalam ilmu perang untuk memenangi pertempuran (Edison 2017). Strategi dalam pembelajaran memiliki fungsi sentral yakni sebagai alat dan cara untuk mencapai tujuan pembelajaran. Guru perlu memilih dan menjalankan strategi pembelajaran sesuai dengan kebutuhan dan tujuan yang telah rumuskan dengan tetap berpedoman pada strategi pembelajaran yang dilakukan Yesus. Penggunaan strategi mengajar Yesus akan berdampak kepada anak apabila guru senantiasa mengembangkan diri dalam mengenal setiap pribadi anak yang diajar.

Strategi yang digunakan Yesus dalam pengajaran-Nya nampak dalam hal pemilihan tempat yang tepat (Matius 5:1), melibatkan peran para murid (Mat. 5:1c), materi pembelajaran dikontekskan dengan pendengarnya (Mat. 5:13-16) dan penggunaan bahan sekitar sebagai alat menyampaikan pengajaran (Mat. 5-7).

\section{Pemilihan Tempat yang Tepat}

Dalam Matius 4:12-17 dikisahkan bahwa Yesus tampil di Galilea lalu naik ke atas bukit. Ini menunjukkan bahwa Yesus memulai pembelajaran dengan memilih tempat. Ia selalu memilih tempat yang tepat. Orang Galilea pada zaman Yesus lebih terbuka kepada pikiran-pikiran baru dari pada orang Yudea. Menurut Yosefus Galilea senang terhadap pembaharuan- 
pembaharuan, ebab itu mereka lebih gampang menerima Injil Kristus (Heer 2000).

Yesus memilih bukit untuk melangsungkan pengajarannya karena la menganggap bahwa bukit adalah tempat yang kondusif dan tepat. Heer mengatakan lereng bukit adalah tempat sunyi, tidak ada gangguan dari orang yang mau lewat. Seandainya Yesus duduk sedikit lebih tinggi di lereng bukit dari pendengar-pendengar-Nya maka semua pendengar itu dengan gampang akan melihat Dia (Heer 2000). Dengan demikian Yesus tidak sembarang dalam melangsungkan pengajaran-Nya tetapi la mampu menentukan waktu dan tempat yang tepat serta nyaman bagi pendengar-Nya.

Hal ini belum maksimal dilaksanakan oleh guru Sekolah Minggu di gereja KIBAID Jemaat Tombang oleh karena seringkali banyak yang terganggu karena kebisingan lalu lintas jalan saat belajar.

\section{Melibatkan Peranan Para Murid}

Melibatkan peranan para murid merupakan salah satu strategi yang Yesus gunakan dalam pengajaran kepada orang banyak (Matius 5:1c). la sadar bahwa peranan murid-murid sangat penting untuk mendukung dalam pelayanan-Nya. Dalam pasal sebelumnya Yesus memanggil beberapa murid terlibat dalam pelayanan di Galilea (4:18-22). Mereka dipanggil untuk suatu misi yang mulia, dipersiapkan dalam pelayanan-Nya. Chapman mengatakan 
mereka mengikut Dia dan belajar dari Dia, bahkan sampai kepada pembelajaran yang praktis (Chapman 1980).

Sujoko mengatakan bahwa Yesus melibatkan para murid melalui proses yang unik. Dia yang mencari mereka, tidak pernah tamat, dan harus tinggal bersama dengan Dia. Hal itu berbeda dari murid-murid para rabi Yahudi, mereka yang mencari guru, ada saatnya mereka tamat dan tidak lagi tinggal bersama dengan rabi mereka (Sujoko 2009). Kitab Matius menampilkan peranan murid-murid dalam kegiatan mengajar dan mendidik. Selain itu, mereka juga diberi kuasa untuk mengikat dan melepaskan (Hakh 2008).

Dari sini nampak bahwa efektifitas proses pembelajaran adalah pelibatan peserta didik. Pelibatan peserta didik dalam proses pembelajaran di gereja KIBAID Jemaat Tombang belum maksimal sebab ada guru yang menerapkannya tetapi ada juga yang tidak.

\section{Materi Pembelajaran Dikontekskan dengan Pendengarnya}

Yesus selalu memberikan pokok pengajaran yang sesuai dengan keadaan pendengarnya. Dia memakai pengalaman-pengalaman pendengarNya untuk mengajar mereka (Mat. 5:13-16). Dia menggunakan kata garam, terang, dan pelita yang mudah dijumpai dan digunakan pendengar-Nya dalam kehidupan sehari-hari (Mat. 5:15). 
Yesus selalu menghubungkan garam dengan tiga macam hal yaitu, kemurnian, bahan pengawet, dan memberikan cita rasa. Garam berguna memberi rasa kepada makanan begitu pula manusia berguna bagi dunia ini. Sama halnya dengan terang dibutuhkan semua orang untuk menunjukkan jalan kepada Allah. Terang berfungsi untuk melihat, membimbing, dan memberi peringatan (Newman 2008). Dampak dari pembelajaran yang demikian banyak orang yang takjub kepada pengajaran Yesus.

Penerapan mengajar dengan memperhatikan konteks belum dilaksanakan juga secara maksimal khususnya belum memperhatikan konteks umur anak di Gereja KIBAID Jemaat Tombang.

\section{Menggunakan Alat Bantu Pembelajaran}

Yesus menggunakan alam dan bahan-bahan yang ada di sekitar untuk menjelaskan pengajaran-Nya. la menggunakan hal-hal yang gampang dimengerti untuk menjelaskan hal-hal yang sulit dipahami dengan contohcontoh konkret. Misalnya Yesus menggunakan garam, terang dan pelita (Matius 5:13-16, 6:22), langit dan bumi (Mat. 5:18,34), anggota tubuh seperti mata, tangan, kaki, kepala, rambut, gigi, pipi (Mat. 5:29-30,35,36) baju dan jubah (5:40) matahari dan hujan (5:45) rumah, lorong, kamar, pintu (6:2,5,6), burung-burung, bunga-bunga, rumput, ladang, api $(6: 26,28,30)$, selumbar dan balok (7:3-5), mutiara, binatang seperti babi dan anjing, ular, ikan, 
domba, serigala $(7: 6,10,15)$ batu, roti $(7: 9,25)$, anggur, semak duri, buah ara, rumput duri, pohon (7:16b-19), dan pasir (7:26).

Yesus menunjukkan objek-objek yang konkrit untuk dilihat. Dia menggunakan bahan-bahan yang ada di sekitar dan mudah di jumpai dalam kehidupan sehari-hari sehingga pendengar mudah memahami ajaran yang disampaikan oleh Yesus.

Berdasarkan hasil penelitian, ternyata guru Sekolah Minggu belum trampil dalam memilih dan menggunakan strategi mengajar. Jadi kompetensi pedagogik guru Sekolah Minggu di Gereja KIBAID Jemaat Tombang berdasarkan Matius 5-7 belum berdampak secara maksimal kepada anak Sekolah Minggu karena guru belum terampil dalam memilih dan menggunakan strategi mengajar yang tepat.

\section{Kreatif Menggunakan Metode Mengajar}

Dalam pemilihan metode pembelajaran sangat diperlukan kreatifitas. Metode yang kreatif meningkatkan antusiasme anak mengikuti pembelajaran. Metode mengajar Yesus akan efektif apabila guru terus melatih diri dalam menguasai beberapa metode yang menarik minat anak.

Dalam penelitian ini tampak bahwa kompetensi pedagogik Yesus berdasarkan Matius 5-7 belum berdampak secara maksimal karena guru Sekolah Minggu kurang kreatif dalam menggunakan metode mengajar, sehingga tidak tertarik mengikuti pembelajaran.

(c) 2021 Simon Runtung, Rini Bunga 


\section{Terampil Menyusun Isi Pembelajaran}

Ferry menjelaskan bahwa khotbah di bukit memberitakan karakteristik yang benar dari kerajaan Allah yang berbeda dengan pemerintahan kaisar saat itu. Pengajaran Yesus di bukit memiliki nilai-nilai spiritual yang agung dan menjadi inspirasi bagi semua orang (Yang 2014). Isi pengajaran Yesus sangat sistematis di dalam Matius 5:3-7:27 yang terdiri atas: Ucapan bahagia (Mat. 5:3-12), garam dunia dan terang dunia (Mat. 5:13-16), Yesus dan hukum Taurat (Mat. 5:17-48), hal memberi sedekah (Mat. 6:1-4), hal berdoa (Mat. 6:5-15), hal berpuasa (Mat. 6:16-18), hal mengumpulkan harta (Mat. 6:19-24), hal kekuatiran (Mat. 6:25-34), hal menghakimi (Mat. 7:1-5), hal yang kudus dan berharga (Mat. 7:6), hal pengabulan doa (Mat. 7:7-11), jalan yang benar (Mat. 7:12-14), hal pengajaran yang sesat (Mat. 7:15-23), dua macam dasar (Mat. 7:24-27). Talan membaginya dalam tiga bagian yaitu, dalam bagian pertama diuraikan tentang prinsip berbahagia (5:1-12), memberi dampak positif bagi dunia $(5: 13-16)$, dan prinsip utama kebenaran tentang hukum Taurat dan Yesus (5:17-48) (Talan 2020).

Yesus cakap menyusun isi pembelajaran-Nya. Isi pembelajaran-Nya sangat berbobot. Ini nampak pada kesan pendengar dalam Matius 7:28, ketika orang banyak takjub mendengar pengajaran-Nya. Para murid dan orang banyak memahami isi pengajaran Yesus dan mereka memberikan respon positif. 


\section{Terampil Menutup Pembelajaran}

Yesus terampil menutup pembelajaran (Mat. 7:24-27), dengan dua hal mendasar dengan bangunan di atas pasir dan batu. Setelah Yesus menutup pengajaran-Nya orang banyak takjub akan apa yang diajarkanNya. Hal tersebut dapat dilihat pada kesan para pendengar pada Matius 7:28. "Dan setelah Yesus mengakhiri perkataan ini, takjublah orang banyak itu mendengar pengajaran-Nya" Pengajaran Yesus mampu menjawab setiap kebutuhan para pendengar-Nya. Matius 7:29. Menjelaskan bahwa Yesus mengajar orang banyak sebagai orang yang berkuasa, tidak seperti ahli-ahli Taurat mereka. Boehlke mengatakan bahwa gaya mengajar Yesus mampu menarik perhatian khalayak ramai yang sudah bosan dengan cara pendekatan guru-guru biasa (Boehlke 2016). Keistimewaan Yesus dalam mengajar bukan hanya karena ia memiliki cara yang menarik dalam mengajar tetapi karena la mengajar dengan kuasa.

Bruggen mengatakan bahwa Khotbah di bukit begitu istimewa bukan hanya karena isinya, melainkan karena di sana Yesus menyimpulkan ajaranNya dengan begitu tegas dan juga karena tempat serta suasananya (Bruggen 2004). Yesus menutup pengajaran-Nya dengan menegaskan di dalam pasal 7: 24,26 setiap orang yang mendengarkan perkataan-Ku ini dan melakukannya. Maksud Yesus dengan pengajarannya ialah bukan saja supaya pengajarannya itu didengar oleh murid-murid atau pendengarnya, 
tetapi juga supaya mereka melakukannya. Bergant dan Karris menjelaskan bahwa khotbah di Bukit ditutup dengan sejumlah hal kontras mengenai keputusan memihak atau melawan Allah. Gambaran mengenai dua jalan dalam Mat. 7:13-14 juga dalam Mat.7:21-23 juga terfokus pada hubungan antara kata dan tindakan. Tidaklah cukup mengatakan Tuhan, Tuhan, karena hanya yang melakukan kehendak Allah yang memberi jalan masuk ke kerajaan-Nya. Dasar kuat yang disebut dalam ayat 24-27 mencakup kata dan perbuatan (Bergant dan Karris 2002). Khotbah di Bukit pun juga diakhiri dengan ucapan berkat kepada mereka yang setia dan kutuk kepada mereka yang tidak menaati-Nya (Mat. 7:24-27) (Setiawan dan Soetapa 2010). Yesus mengakhiri khotbah di Bukit dengan penegasan kepada para murid dan pendengar-Nya agar melakukan seluruh pengajaran yang telah disampaikan.

\section{Cara Mengimplementasikan Kompetensi Pedagogik Yesus}

Berdasarkan hasil interpretasi terhadap kompetensi pedagogik Yesus berdasarkan Matius 5-7, berikut adalah beberapa hal yang dapat diimplementasikan ke dalam pengajaran Sekolah Minggu di Gereja KIBAID Jemaat Tombang-Sangalla'.

\section{Penuh Perhatian dan Kasih terhadap Peserta Didik}

Perhatian dan kasih berarti kepekaan kepada kebutuhan sesama. Yesus menekankan pentingnya kasih yang diwujudkan dalam perbuatan 
(Brownlee 2004). Demikian juga dalam pembelajaran seorang guru harus menunjukkan kasih dan perhatian kepada peserta didik. Hal-hal yang harus dilakukan GSM ialah memberikan perhatian kepada peserta didik melalui pembinaan, bimbingan, mengunjungi yang sakit, dan memberikan perhatian kepada anak yang berkebutuhan khusus serta anak yang susah diatur.

\section{Mampu Mengarahkan Peserta Didik}

Yesus mampu mengarahkan peserta didik untuk mencapai tujuan pembelajaran, yakni menjadi garam dan terang dunia (Mat. 5:13-16). Teks ini berbicara mengenai hakikat dan sekaligus tugas pemuridan. Martasudjita mengatakan bahwa para murid Yesus adalah seumpama garam yang memberikan rasa, juga seumpama terang yang harus memberi cahaya sekitarnya (Martasudjita 2003). Yesus dalam pengajaran-Nya menunjukkan bahwa la mengenal karakteristik murid yang mendengar pengajaran-Nya. Sinlae mengatakan bahwa Tuhan Yesus mampu mengarahkan, menuntun dan membimbing murid mengerti pengajaran yang diberikan sehingga pengajaran-Nya membekas dalam ingatan para murid. Dengan demikian mengenal karakteristik murid-murid merupakan hal yang sangat penting. Pengenalan seorang guru terhadap karakteristik murid akan mempermudah guru mengajar dan membimbing murid kepada keberhasilan (Sinlae 2019).

Salah satu tugas penting seorang GSM adalah mengarahkan peserta didik mampu bertumbuh dalam pengenalan yang benar akan Kristus yang 
berdampak bagi lingkungan sekitar. Ketika mampu mengarahkan anak melakukan pembelajaran maka berhasil menuntun kepada perubahan dan perkembangan. Karena itu implementasi kompetensi pedagogik Yesus berdasarkan Mat. 5-7 di Gereja KIBAID Jemaat Tombang ialah mampu mengarahkan peserta didik.

\section{Melandasi Pengajaran dengan Doa}

Pengajaran Yesus kepada pengikutnya disertai dengan doa (6:5-18, 7:7-11). Gianto mengatakan bahwa ajaran mengenai perlunya berdoa tanpa jemu-jemu dengan iman untuk kesiagaan dan pengabdian kepada kehendak Bapa. Doa adalah pelayanan yang harus ditaruh pada kedudukan yang pertama. Iblis selalu melancarkan siasatnya untuk menaruh hal-hal lain dan menempatkan doa pada urutan terakhir (Gianto 2005).

Doa adalah hal yang sangat penting yang harus dilakukan setiap guru maupun peserta didik dengan tidak jemu-jemu. Berdasarkan hasil observasi dan wawancara bahwa ketika guru mampu mengimplementasikan pengajarannya yang dilandasi dengan doa maka tujuan dapat tercapai secara efektif.

GSM hendaknya melandasi setiap pengajarannya dengan doa, mendoakan anak-anak yang diajar sehingga tidak hanya lewat materi pembelajaran saja mendukung mereka tetapi yang terutama ialah lewat doa. 


\section{Menuntun Peserta Didik Melakukan Kebenaran}

Yesus menuntun peserta didik melakukan kebenaran. Pokok yang diajarkan untuk menuntun melakukan kebenaran adalah Yesus dan hukum taurat (5:17-48), hal memberi sedekah (6:1-4), hal mengumpulkan harta (6:19-24) dan hal kekuatiran, (6:25-34) hal menghakimi (7:1-5) dan hal yang kudus dan berharga (7:6), tentang jalan yang benar (7:12-14), hal pengajaran sesat dan dua macam dasar (7:15-27). Yesus sebagai sumber kebenaran yang sejati menuntut agar para pengikut-Nya dapat meneladani-Nya melakukan kebenaran. Coleman mengatakan bahwa Yesus sadar mengenai kebenaran-kebenaran tentang Dia akan terwujud pada waktunya, asal saja para murid bersedia taat. Orang yang tidak pernah belajar menjadi pengikut terlebih dahulu tidak akan bisa menjadi pemimpin. Yesus tahu bahwa perkembangan karakter dan tujuan akan terjadi melalui ketaatan.

Keberhasilan seorang guru adalah ketika peserta didik mampu melakukan tujuan pengajaran yang dirumuskan, yaitu melakukan kebenaran mengikuti keteladan Yesus Sang guru Agung yang merupakan sumber kebenaran itu sendiri. Berdasarkan penelitian, GSM di gereja KIBAID Jemaat Tombang bahwa menuntun peserta didik melakukan kebenaran harus terus diupayakan. Guru harus terus memantau perkembangan setiap peserta didik sehingga kebenaran yang diajarkan dapat diaplikasikan dalam kehidupan sehari-hari serta membawa dampak yang positif bagi orang lain. Tidak hanya 
bagi peserta didik guru juga mengupayakan memberikan teladan dalam melakukan kebenaran agar dapat diteladani oleh peserta didik.

\section{KESIMPULAN}

Berdasarkan hasil penelitian tentang kompetensi pedagogik Yesus berdasarkan Matius 5-7 dan implementasinya dalam pengajaran sekolah Minggu di Gereja KIBAID Jemaat Tombang, maka peneliti menarik kesimpulan bahwa pengajaran belum berdampak secara maksimal kepada anak. Hal tersebut disebabkan GSM belum terampil dalam memilih dan menggunakan strategi mengajar Yesus, serta kurang kreatif dalam menggunakan metode mengajar Yesus.

Cara mengimplementasikan kompetensi pedagogik Yesus berdasarkan berdasarkan pengajaran Yesus dalam Matius 5-7 di kalangan GSM di Gereja KIBAID Jemaat Tombang yakni, penuh perhatian dan kasih terhadap peserta didik dalam menanamkan nilai-nilai moral, menyampaikan Firman Tuhan memberikan dukungan moril kepada anak yang mengalami dukacita, kesusahan melalui pelayanan diakonia. GSM juga harus mampu mengarahkan peserta didik dalam pertumbuhan iman dengan memberikan pembinaan-pembinaan melalui kegiatan-kegiatan gereja lokal, klasis maupun di masyarakat, memotivasi peserta didik mengaktualiasasikan potensi yang dimiliki. Guru perlu melandasi pengajaran dengan doa di awal dan di akhir kelas, mendoakan anak-anak sekolah minggu dalam berbagai pergumulan. 
Selain itu GSM juga perlu melatih peserta didik berdoa, menuntun mereka melakukan kebenaran Firman Tuhan, hidup sesuai dengan kehendak Tuhan.

Oleh karena itu hendaknya guru hendaknya menyusun program perencanaan pembelajaran terstruktur secara pribadi dan kelompok, juga terus mengembangkan diri dalam hal pendekatan kepada anak seperti mengikuti pelatihan-pelatihan dan seminar-seminar GSM.

\section{DAFTAR PUSTAKA}

Bergant, Dianne, dan Robert J. Karris. 2002. Tafsir Alkitab Perjanjian Baru. Yogyakarta: Kanisius.

Boehlke, Robert R. 2016. Sejarah Perkembangan Pikiran \& Praktek Pendidikan Agama Kristen 2. Jakarta: BPK Gunung Mulia.

Brake, Andrew. 2019. Keunggulan Kristus dan Kerajaan Allah. Makassar: STT Jaffray.

Brownlee, Malcolm. 2004. Tugas Manusia dalam Dunia Milik Tuhan. Jakarta: BPK Gunung Mulia.

Bruggen, Jakob van. 2004. Kristus di Bumi. Jakarta: BPK Gunung Mulia.

Chapman, Adina. 1980. Pengantar Perjanjian Baru. Bandung: Kalam Hidup.

Darmawan, I Putu Ayub. 2014. Menjadi Guru yang Terampil. Bandung: Kalam Hidup.

Edison, Thomas. 2017. 52 Metode Mengajar. Bandung: Kalam Hidup.

Ento, Feri Fajar. 2019. Metanoia. Surakarta: CV. Sejati Mitra Mandiri.

Gianto, Agustinus. 2005. Langkah-Nya, Langkahku. Semarang: Kanisius.

Hakh, Samuel Benyamin. 2008. Pemberitaan tentang Yesus. Bandung: Jurnal Info Media.

Hamalik, Oemar. 2009. Proses Belajar Mengajar. Jakarta: PT. Bumi Aksara.

Heer, J.J. de. 2000. Tafsiran Alkitab Injil Matius 1-22. Jakarta: BPK Gunung Mulia.

(c) 2021 Simon Runtung, Rini Bunga 
Homrighausen, E.G., dan I.H. Enklaar. 2013. Pendidikan Agama Kristen. Jakarta: BPK Gunung Mulia.

Martasudjita, E. 2003. Sakramen-sakramen Gereja. Yogyakarta: Kanisius.

Muliayan, A.Z. 2010. Rahasia Menjadi Guru Hebat. Surabaya: Grasindo.

Nainggolan, John M. 2007. Menjadi Guru Agama Kristen. Bandung: Generasi Info Media.

Newman, Barclay M. 2008. Pedoman Penafsiran Alkitab Injil Matius. Jakarta: LAI.

Prince, J.M. 1975. Yesus Guru Agung. Bandung: Lembaga Literatur Baptis.

Rosyada, Dede. 2017. Profesionalisme Guru. Depok: Kencana.

Setiawan, Nur Kholis, dan Djaka Soetapa. 2010. Meniti Kalam Kerukunan. Jakarta: BPK Gunung Mulia.

Sidjabat, B.S. 2009. Mengajar Secara Profesional. Bandung: Kalam Hidup.

Sinlae, Ronald Yohanes. 2019. "Kompetensi Pedagogik Tuhan Yesus dalam Injil Matius 5-7." Exelcis Deo 4.

Sujoko, Albertus. 2009. Identitas Yesus dan Misteri Manusia. Yogyakarta: Kanisius.

Sumiyatiningsih, Dien. 2006. Mengajar dengan Kreatif dan Menarik. Yogyakarta: Penerbit ANDI.

Talan, Yesri. 2020. Pola Dasar Hidup Kristen: Kajian Teologis Terhadap Khotbah Yesus Di Bukit. Bengkulu: Permata Rafflesia.

Verkuyl, J. 2002. Khotbah di Bukit. Jakarta: BPK Gunung Mulia.

Yang, Ferry. 2014. "Kerajaan Allah: Sebuah Tinjauan Eksegesis.” Veritas 15 (1): 35-59. 